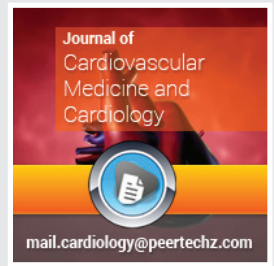

\title{
Journal of Cardiovascular Medicine and Cardiology
}

Mohamed Abdel-shafy Tabl'*, Khaled Emad El-Rabbat' ${ }^{\prime}$ Eman Said Elkeshk' and Gamal Mohamed Gharib ${ }^{2}$

'Department of Cardiology, Benha University, Benha, Egypt

${ }^{2}$ National Heart Institute, Cairo, Egypt

Received: 10 December, 2018

Accepted: 29 January, 2019

Published: 30 January, 2019

*Corresponding author: Mohamed Abdel-shafy Tabl, Department of Cardiology, Benha University, Benha, Egypt, E-mail:mshafytabl@yahoo.com

https://www.peertechz.com

Keywords: ST elevation MI; Primary PCl; Deferred stenting

Check for updates
Research Article

\section{Deferred stent implantation in patients with ST segment elevation myocardial infarction with high thrombus burden}

\section{Abstract}

Recent guidelines recommend against deferred stenting as a routine strategy in STEMI patients.

Objectives: current study aimed to assess whether deferred stenting strategy in primary $\mathrm{PCI}$ might reduce angiographic or in-hospital major adverse cardiac events in comparison to immediate stenting.

Methods: one hundred patients of STEMI with high thrombus burden divided equally into; 50 patients (group 1) treated with immediate stenting and 50 patients (group 2) treated with deferred stenting. Procedural angiographic events were the primary endpoints, while in hospital MACE were designed as secondary endpoints.

Results: patients of deferred stenting group had statistically significant reduction of distal embolization, slow flow and no reflow $(P$ value $=0.016)$. In contrast, deferred strategy didn't improve the short term clinical outcomes. Composite of MACEs was statistically significant in the deferred stenting group $(20 \%)$ versus only $(6 \%)$ in the immediate stenting group $(P$ value $=0.037$ ).

Conclusion: Deferred stenting in patients with STEMI those with high thrombotic burden improves only the angiographic outcomes but could not improve the short term clinical outcomes in comparison to immediate stenting. Deferred stenting shouldn't be used as a routine strategy in STEMI patients.

\section{Introduction}

Reduced flow to the vascular bed of the infarct-related artery (IRA) is observed in a considerable number of patients treated with primary PCI, especially after stent implantation, even in patients with a normal epicardial flow [1]. Postponed stent implantation (deferred strategy) may potentially limit the risk of distal coronary embolization and may improve the prognosis [2]. In previous studies deferred stenting strategy decreased the rates of angiographic events (distal emboli, no-reflow) with reduction of infarct size [3]. In addition to significant reduction in congestive heart failure, re infarction and cardiac mortality [4]. On the other hand, other randomized trials showed deferred strategy to have unexpected hazards; possible acute coronary re occlusion in the interval between index reperfusion and actual stent implantation in addition to prolonged hospital stay and increased immediate costs [5]. The aim of the current study is to assess whether deferred strategy in primary PCI might reduce angiographic and/or in-hospital clinical major adverse cardiac events (MACE) in comparison to immediate stenting strategy.

\section{Patients and Methods}

\section{Study population}

This multi centers, prospective trial targeted patients who presented with ST-segment elevation myocardial infarction (STEMI) and treated with primary PCI in Benha University Hospital and National Heart Institute in Cairo.

\section{Inclusion criteria}

- Patients with a high angiographic thrombus burden (thrombus burden score $\geq 3$ ) [6].

- Patients who gained at least TIMI flow II or III spontaneously or after manual aspiration and/or balloon dilatation.

\section{Study protocol}

One hundred patients subjected either to immediate or deferred stenting strategies according to discretion of the operator. They were divided into two main groups based on the strategy of management: 
Group 1: included 50 patients who were treated with conventional immediate stenting.

Group 2: included 50 patients who were treated with deferred stenting.

The study was explained to all participants and /or their relatives and informed consent was taken from all subjects of the study before starting the study. Approval of the ethical committee of (Benha faculty of medicine) according to declaration of Helsinki for ethical principles of medical research involving human subjects was obtained.

\section{Methods}

\section{Full medical history, clinical examination and ECG}

Age and gender, risk factors as diabetes, hypertension and smoking were defined according to recent guidelines [7]. History of prior angina, PCI or CABG was documented. Detailed clinical examination with concern to patient's Killip class on the diagnosis, guide the therapy and to monitor arrhythmias.

\section{Laboratory investigation}

Kidney function tests, complete blood count, prothrombin time, concentration and international normalized ratio (INR) on admission. Cardiac enzymes (CK-MB and cardiac troponin) tested on admission and after intervention.

\section{Echocardiography assessment}

Using VIVID S5, GE machine, before and within hospital stay with emphasis on: LV end diastolic and end systolic dimensions, Left ventricular ejection fraction EF\% (by Simpson method) or presence of mechanical complication.

\section{Percutaneous coronary intervention}

Coronaries were accessed through femoral or radial artery, according to the operator decision. Variety of supporting guiding catheters and floppy wires were used according to the feasibility, suspected culprit vessel and sometimes to the operator decision. The patients who had intracoronary thrombi with TIMI flow II or less subjected to wire introduction, thrombus aspiration using suction device and/or dilation of the lesion with an undersized balloon to achieves at least TIMI flow II.

\section{Study endpoints}

Procedural angiographic events were the primary endpoints, while in hospital major adverse cardiovascular events or bleeding complications were designed as secondary endpoints.

\section{Primary end points}

The angiographic complications defined as follow:

- Distal embolization as the presence of filling defects in or cut-off of a distal branch. admission with standard twelve lead ECG aimed to establish

- Slow flow as TIMI grade 2 flow at the end of the procedure.

- No reflow as TIMI grade 1 or 0 flow in the distal infarctrelated artery in the absence of an occlusion at the treatment site or evidence of distal embolization [8].

\section{Secondary end points}

Composite endpoint of cardiac mortality, non-fatal myocardial infarction and/or target vessel revascularization (TVR) was reported [9]. Hemodynamic instability as cardiogenic shock or pulmonary edema was considered. Urgent revascularization in the form of PCI to infarct related artery (IRA) was assessed.

Bleeding complications were defined according to Global Utilization of Streptokinase and Tissue-Plasminogen Activator for Occluded Coronary Arteries (GUSTO) score into: Severe or life-threatening, moderate or mild bleeding [10].

\section{Statistical analysis}

The association between variables and treatment groups was investigated by Mann Whitney $\mathrm{U}$ and Chi-square tests. A $\mathrm{p}$ value less than 0.05 were considered significant (2-sided). All analyses were carried out using Stata 12 software (StataCorp LP, College Station, Texas).

\section{Results}

\section{Demographic, clinical and echocardiographic data}

Male gender represented ( $74 \%$ ) of the study populations with mean age of 57 years. The baseline demographic, clinical and echocardiographic characteristics were matched with nonsignificant differences between both groups. All data were demonstrated in table 1.

\section{Angiographic data}

Femoral approach was the common access for coronary

Table 1: Comparison between two groups regarding the demographic, clinical and echocardiographic data

\begin{tabular}{|c|c|c|c|c|}
\hline Demographic data & Group 1 & Group 2 & Test & P-value \\
\hline Mean age \pm SD & $57.5 \pm 10.3$ & $56.5 \pm 11.1$ & \multirow{2}{*}{0.435} & 0.664 \\
\hline Median (Range) & $60(33-72)$ & $58(36-75)$ & & \\
\hline Male & $36(72 \%)$ & $38(76 \%)$ & \multirow{2}{*}{$0.208 \ddagger$} & 0.648 \\
\hline Female & $14(28 \%)$ & $12(24 \%)$ & & \\
\hline Hypertension & $30(60 \%)$ & $27(54 \%)$ & $0.367 \ddagger$ & 0.545 \\
\hline Diabetes & $25(50 \%)$ & $24(48 \%)$ & $0.040 \ddagger$ & 0.841 \\
\hline Smoking & $22(44 \%)$ & $24(48 \%)$ & $0.161 \ddagger$ & 0.688 \\
\hline Prior angina & $12(24 \%)$ & $15(30 \%)$ & $0.457 \ddagger$ & 0.499 \\
\hline Killip Class I & $23(46 \%)$ & $25(50 \%)$ & & \\
\hline Class II & $14(28 \%)$ & $15(30 \%)$ & & \\
\hline Class III & $9(18 \%)$ & $8(16 \%)$ & $0.843 \ddagger$ & 0.839 \\
\hline Class IV & $4(8 \%)$ & $2(4 \%)$ & & \\
\hline Total ischemic time (h) Mean \pm SD & $5.7 \pm 2.4$ & $5.9 \pm 2.6$ & $-0.306 \cdot$ & 0.760 \\
\hline LVEF (\%) Mean \pm SD & $47.8 \pm 7.4$ & $48.6 \pm 6.5$ & $-0.719 \cdot$ & 0.472 \\
\hline Mann Whitney U test. $\ddagger$ Chi-square test. & & & \\
\hline & & & & 0.02 \\
\hline
\end{tabular}

Citation: Tabl MA, El-Rabbat KE, El-keshk ES, Gharib GM (2019) Deferred stent implantation in patients with ST segment elevation myocardial infarction with high thrombus burden. J Cardiovasc Med Cardiol 6(1): 001-005. DOI: http://doi.org/10.17352/2455-2976.000080 
angiography; radial approach is achieved in (16\% and $14 \%$ ) in group 1 and group 2 respectively. LAD represented as the IRA in group 1 and group $2(50 \%$ and $52 \%)$ respectively, followed by RCA in (32\% and $26 \%)$ then LCX in $(18 \%$ and $22 \%$ ). Only culprit lesions were done for all patients including patients with cardiogenic shock according to ESC guidelines for coronary revascularization in 2018 [11]. Initial TIMI flow (at initial angiography) was comparable in both groups; $(\mathrm{P}$ value $=0.874)$, the same as thrombus burden score that was nearly equal in both groups; $(P$ value $=0.072$ ) $($ Table 2$)$. Culprit residual lesion length and culprit residual stenosis was comparable after initial thrombectomy procedure $(\mathrm{P}$ value $=$ $0.49 \& 0.91$ ) (Table 2).

Tirofiban $(25 \mu \mathrm{g} / \mathrm{kg}$ bolus followed by $0.15 \mu \mathrm{g} / \mathrm{kg} / \mathrm{min}$ maintenance) or eptifibitide $(180 \mu \mathrm{g} / \mathrm{kg}$ bolus, infusion 2 $\mu \mathrm{g} / \mathrm{kg} / \mathrm{min}$ ) was administered intravenously immediately after initial PCI in all patients with deferred stenting and maintained for 20-48 hours, renal adjusted doses were used in patients with renal impairment. Only patients with major thrombotic complications (no or slow flow or significant distal embolization) in immediate stenting group were received GP IIb IIIa inhibitors (8 patients; $16 \%$ for a mean duration of $24 \mathrm{~h}$ ). Coronary angiography in the delayed stenting group was performed 24 to $48 \mathrm{~h}$ after initial angiography with mean duration of $36 \mathrm{~h}$. Stenting was needed less frequently in the deferred stenting group. 12 patients had no longer significant coronary stenosis at the time of the delayed procedure and this was statistically significant $(\mathrm{P}$ value $<0.001)$.

Primary endpoints (angiographic outcomes): Among patients of deferred stenting group no any cases of no reflow recorded, while 7 cases occurred in immediate stenting group $(14 \%)(P$ value $=0.016)$

Among patients of immediate stenting group, TIMI III flow was achieved in 41 patients $(82 \%)$, while composite of slow flow and no re flow occurred in 9 cases (18\%) (Table 3). However, the rate of patients achieving TIMI grade III flow at the end of PCI procedure was higher in the deferred stenting group compared with immediate stenting group; this was statistically non-significant $(94 \%$ and $82.0 \%)(\mathrm{P}$ value $=0.065)($ Table 3$)$. Distal embolization occurred more frequently in immediate stenting group, 7 patients (14\%) (Five had small distal filling defect and two had abrupt cut off distally) versus 5 patients $(10 \%)$ in the deferred stenting group (four had just small filling defect distally in the infarct related vessel, one had abrupt cut off distally $)(P$ value $=0.538)($ Table 3$)$.

Secondary endpoints (clinical outcome): Major adverse cardiac events were observed in the two groups during the initial hospital stay that was ranged from two to five days. The composite of MACEs was statistically significant in the deferred stenting group $(20 \%)$ versus only $(6 \%)$ in the immediate stenting group $(\mathrm{P}$ value $=0.037)($ Table 4$)$.

Regarding cardiac mortality, One patient died in immediate stenting group secondary to cardiogenic shock while 5 patients died in deferred stenting group ( 2 after cardiogenic shock
Table 2: Comparison between the studied groups regarding the initial angiographic data.

\begin{tabular}{|c|c|c|c|c|}
\hline Initial angiographic data & Group 1 & Group 2 & Test & P-value \\
\hline Femoral approach & $42(84 \%)$ & $43(86 \%)$ & \multirow{2}{*}{$0.078 \ddagger$} & \multirow{2}{*}{0.779} \\
\hline Radial approach & $8(16 \%)$ & $7(14 \%)$ & & \\
\hline \multicolumn{5}{|c|}{ Infarct related artery } \\
\hline Proximal LAD & $16(32 \%)$ & $13(26 \%)$ & \multirow{7}{*}{$6.097 \ddagger$} & \multirow{7}{*}{0.412} \\
\hline Mid LAD & $9(18 \%)$ & $13(26 \%)$ & & \\
\hline Proximal LCX & $2(4 \%)$ & $2(4 \%)$ & & \\
\hline Mid LCX & $7(14 \%)$ & $9(18 \%)$ & & \\
\hline Proximal RCA & $6(12 \%)$ & $3(6 \%)$ & & \\
\hline Mid RCA & $9(18 \%)$ & $5(10 \%)$ & & \\
\hline Distal RCA & $1(2 \%)$ & $5(10 \%)$ & & \\
\hline \multicolumn{5}{|c|}{ Initial TIMI flow } \\
\hline TIMI 0 & $26(52 \%)$ & 27 (54\%) & \multirow{4}{*}{$0.696 \ddagger$} & \multirow{4}{*}{0.874} \\
\hline TIMI I & $13(26 \%)$ & $10(20 \%)$ & & \\
\hline TIMI II & $6(12 \%)$ & $8(16 \%)$ & & \\
\hline TIMI III & $5(10 \%)$ & $5(10 \%)$ & & \\
\hline \multicolumn{5}{|c|}{ Initial thrombus burden score } \\
\hline Mean \pm SD & $4.38 \pm 0.73$ & $4.12 \pm 0.75$ & 1.800 & 0.072 \\
\hline \multicolumn{5}{|c|}{ TIMI flow } \\
\hline TIMI II & $19(38 \%)$ & $16(32 \%)$ & & \\
\hline TIMI III & $28(56 \%)$ & $34(68 \%)$ & & \\
\hline Thrombus burden score Mean \pm SD & $3.82 \pm 0.63$ & $3.64 \pm 0.49$ & 1.373 & 0.170 \\
\hline $\begin{array}{l}\text { Culprit lesion length }(\mathrm{mm}) \text { Mean } \\
\qquad \pm \mathrm{SD}\end{array}$ & $26.04 \pm 7.62$ & $27.04 \pm 7.78$ & $-0.689 \cdot$ & 0.491 \\
\hline $\begin{array}{l}\text { Culprit lesion stenosis (\%) Mean } \\
\qquad \pm \mathrm{SD}\end{array}$ & $85.3 \pm 8.5$ & $84.8 \pm 9.4$ & 0.103 & 0.918 \\
\hline
\end{tabular}

Table 3: Comparison between the studied groups regarding the angiographic outcome.

\begin{tabular}{|c|c|c|c|c|}
\hline Angiographic outcome & Group 1 & Group 2 & Test & P-value \\
\hline TIMI II & $9(18 \%)$ & $3(6 \%)$ & \multirow{2}{*}{$3.409 \ddagger$} & 0.065 \\
\hline TIMI III & $41(82 \%)$ & $47(94 \%)$ & & \\
\hline Normal flow & $42(84 \%)$ & $47(94 \%)$ & & \multirow{2}{*}{0.016} \\
\hline Slow flow & $1(2 \%)$ & $3(6 \%)$ & \multirow{2}{*}{$8.281 \ddagger a$} & \\
\hline No reflow & $7(14 \%)$ & $0(0 \%)$ & & \\
\hline Distal embolization & $7(14 \%)$ & $5(10 \%)$ & & \\
\hline
\end{tabular}

$\ddagger$ Chi-square test.

and 3 with sudden cardiac death), this was statistically non significant $(P$ value $=0.12)($ Table 4$)$. Due to recurrence of symptoms within 48 hours after the procedure, target vessel revascularization (TVR) was needed for only one patient in the immediate stenting group while was needed for 3 patients in deferred stenting group $(\mathrm{P}$ value $=0.85)($ Table 4$)$. One patient complicated with re-infarction in the immediate stenting group versus 2 patients in the deferred stenting group ( $P$ value $=0.56$ ). Enhanced antithrombotic therapies showed no increase in major or moderate bleeding in the deferred stenting group compared with the immediate stenting group , Minor hemorrhagic complications were observed in 3 patients $(6 \%)$ in deferred stenting group versus 2 patients $(4 \%)$ in immediate stenting group $(\mathrm{P}$ value $=0.64)($ Table 4$)$. 
Table 4: Comparison between the studied groups regarding the clinical outcomes of hospital stay.

\begin{tabular}{|c|c|c|c|c|}
\hline Clinical outcomes & Group 1 & Group 2 & Test & P-value \\
\hline Composite of MACEs & $3(6 \%)$ & $10(20 \%)$ & $4.332 \ddagger$ & 0.037 \\
\hline Re-infarction & $1(2 \%)$ & $2(4 \%)$ & $0.325 \ddagger$ & 0.56 \\
\hline TVR & $1(2 \%)$ & $3(6 \%)$ & & 0.33 \\
\hline Cardiac mortality & $1(2 \%)$ & $5(10 \%)$ & & 0.12 \\
\hline Major bleeding & - & - & & 0.64 \\
\hline Minor bleeding & $2(4 \%)$ & $3(6 \%)$ & & $0.211 \ddagger^{\mathrm{F}}$ \\
\hline
\end{tabular}

$\ddagger$ Chi-square test. $\ddagger^{\mathrm{F} F i s h e r ' s ~ e x a c t ~ t e s t . ~}$

\section{Discussion}

Percutaneous coronary intervention (PCI) has emerged as the strategy of choice for re-establishing effective flow in occluded IRA in patients with STEMI [12]. While immediate PCI is often the preferred strategy in this situation, distal embolization is still observed in large percentage of patients after primary PCI, and is associated with incomplete ST segment resolution, increased necrosis volume and poor outcome with increase in 5-year mortality [13]. Delaying or deferred stenting in primary PCI has been investigated as an option to reduce microvascular obstruction and preserve microcirculatory function in two small trials with conflicting results [14]. In current study, TIMI III flow was achieved in majority of deferred stenting group $(94 \%)$ versus only $(82 \%)$ in immediate stenting group ( $\mathrm{P}$ value $=0.065)($ Table 3$)$. The thrombus related angiographic complications as no reflow were completely absent in deferred stenting group $(0 \%)$ while detected in seven patients of immediate stent group $(14 \%)(P$ value $=0.016)($ Table 3$)$. Distal embolization was occurred less frequently in deferred stenting group $(10 \%$ versus $14 \%)(\mathrm{P}$ value $=0.53)($ Table 3$)$. Current study showed better angiographic outcomes for deferred stenting strategy. In comparable to these results, the incidence of no or slow flow varies in different studies in patients directly revascularized for acute myocardial infarction from $12-30 \%$. Tang et al in 2011 showed that stent implantation appears to further increase the risk of no reflow in patients undergoing primary PCI [15]. During acute phase of STEMI, the release of vasoconstrictive substances from platelets may explain the reduction in TIMI flow during stent deployment at highpressure balloon inflation so postponed stenting allows both spontaneous structural modifications and pharmacological treatment to act with time on the platelet thrombus and fibrin rich clot, resulting in enhancement of clot lysis and dissolution of thrombus and so less distal embolization. Meanwhile, deferred PCI was therefore protectively associated against these complications. In addition, the deferred stenting approach may avoid unnecessary stent implantation. In current study, stenting was less frequently needed in the deferred stenting group. 12 patients had no longer significant coronary stenosis at the time of the delayed procedure and this was statistically significant; ( $P$ value $<0.001$ ). In correlation with current study, Cafri et al in 2004 concluded that stent implantation is avoided in $(22.6 \%)$ patients underwent delayed PCI [16]. In addition, deferred stenting was associated with slightly shorter stent length $(26.00 \pm 7.49$ versus $26.04 \pm 7.62)(P$ value $=0.993)$. This could be explained with spontaneous and pharmacological- induced angiographic changes of the vessel and lesion within time. Shorter stents that can be implanted secondarily after first delay could have lower rates of long-term restenosis than longer stents implanted in emergency.

As the results of angiographic outcomes, it was believed that deferred stenting would provide some clinical potential advantages that could reduce MACEs in comparison to immediate stenting. The above-mentioned angiographic advantages were not translated into significant clinical benefit in current study. MACEs were observed in the two groups during the initial hospital stay and also observed during the period between initial coronary angiogram and deferred PCI.

Composite of cardiac mortality, TVR and re infarction showed statistically significant decrease in immediate stenting group $(6 \%$ versus $20 \%)(\mathrm{P}$ value $=0.037)($ Table 4$)$. TVR was needed in only one patient in the immediate stenting group while TVR was needed in three patients in deferred stenting group within 48 hours after the initial procedure. Documented re-infarction occurred in only one patient of immediate stenting group while 2 patients had re-infarction in deferred stenting group. Previously, the results of Meneveau at al. in 2009 showed no statistically significant differences in terms of MACEs between delayed or immediate stenting strategies ( $\mathrm{P}$ value $=0.64$ ) [17]. More recently, in the larger deferred versus conventional stent implantation trial [The Third DANish Study of Optimal Acute Treatment of Patients with ST-segment Elevation Myocardial Infarction: DEFERred stent implantation in connection with primary PCI (DANAMI 3-DEFER)]. 1215 STEMI patients were included; there was no effect on the primary clinical outcome (composite of death, non-fatal MI, or ischaemia-driven revascularization of non-IRA lesions) over a median follow-up of 42 months between the two strategies [18]. As regard bleeding complications, no increase in major or moderate bleeding in the deferred stenting group compared with the immediate stenting group, Minor hemorrhagic complications were observed in $(6 \%)$ of deferred stenting group versus $(4 \%)$ in immediate stenting group ( $\mathrm{P}$ value $=1.0$ ) (Table 4). In agreement, there was no more major bleeding complication noted in the study of Tang et al. [19].

\section{Conclusion}

Deferred stenting in patients with STEMI especially those with high thrombotic burden improves the angiographic outcomes but could not improve the short term clinical outcomes in comparison to immediate stenting. Deferred stenting shouldn't be a routine strategy in STEMI patients. Further evaluation in adequately powered trials with larger number of patients and longer follow up duration are awaited to confirm the clinical benefit of this strategy in this group of population.

\section{References}

1. Ndrepepa G, Tiroch K, Fusaro M (2010) 5-year prognostic value of noreflow phenomenon after percutaneous coronary intervention in patients with acute myocardial infarction. J Am Coll Cardiol 55: 83-89. Link: https://goo.gl/MWzKwq 
2. Meneveau N, Seronde M, Descotes-Genon V, Dutheil J, Chopard R, et al. (2009) Immediate versus delayed angioplasty in infarct-related arteries with TIMI III flow and ST segment recovery: a matched comparison in acute myocardial infarction patients. Clin Res Cardiol 98: 257-264. Link: https://goo.gl/4ni15n

3. Kim J, Choi D, Jang Y, Lee CJ, Lee SH, et al. (2010) Efficacy of high-dose atorvastatin loading before primary percutaneous coronary intervention in ST-segment elevation myocardial infarction: the STATIN STEMI trial. JACC Cardiovasc Interv 3: 332-339. Link: https://goo.gl/bfkDYX

4. Di Pasquale P, Cannizzaro S, Parrinello G, Giambanco F, Vitale G, et al. (2006) Is delayed percutaneous coronary intervention better than immediate in reperfused myocardial infarction? Six months follow up findings. J Thromb Thrombolysis 21: 147-157. Link: https://goo.gl/J2C4vo

5. Belle L, Motreff $P$, Mangin L, Rangé G, Marcaggi X, et al. (2016) Comparison of immediate with delayed stenting using the Minimalist Immediate Mechanical Intervention approach in acute ST-segment-elevation myocardial infarction: The MIMI study. Circ Cardiovasc Interv 9: e003388. Link: https://goo.gl/R13por

6. Gibson CM, Lemos JA, Murphy SA, Marble SJ, McCabe $\mathrm{CH}$, et al. (2001) Combination therapy with abciximab reduces angiographically evident thrombus in acute myocardial infarction: a TIMI 14 substudy. Circulation 103 2550-2554. Link: https://goo.gl/2TM9xp

7. Massimo F, Arnow H, Christian A, Albus C, Brotons C, et al. (2016) European Guidelines on cardiovascular disease prevention in clinical practice. Eur Heart Journal 37: 2315-2381. Link: https://goo.gl/7Ea7ek

8. Nicoli G, Spaziani C, Marino M, Pontecorvo ML, Cosentin N, et al. (2010) Effect of chronic aspirin therapy on angiographic thrombotic burden in patients admitted for a first ST-elevation myocardial infarction. Am J Cardiol 105: 587 591. Link: https://goo.gl/FFsY3Q

9. Andreson J, Adams C, Antman E, Bridges CR, Califf RM, et al. (2007) ACC/ AHA 2007 guidelines for the management of patients with unstable angina/ non-ST elevation myocardial infarction: A report of the American College of Cardiology/American Heart Association Task Force on Practice Guidelines. J Am CollCardiol 50: e1-e157. Link: https://goo.gl/6udgYw

10. Iwakura K, Ito H, Kawano S, Okamura A, Kurotobi T, et al. (2006) Chronic pre-treatment of statins is associated with the reduction of the no-reflow phenomenon in the patients with reperfused acute myocardial infarction. Eur Heart J 27: 534-539. Link: https://goo.gl/pRja52

11. Franz-Josef N, Miguel Sousa-U, Anders A (2018) ESC/EACTS Guidelines on myocardial revascularization, Eur Heart Journal 1-96. Link: https://goo.gl/1JzTTr

12. Henriques J, Zijlstra F, Ottervanger S, de Boer MJ, van t Hof AW, et al. (2002) Incidence and clinical significance of distal embolization during primary angioplasty for acute myocardial infarction. Eur Heart J 23: 1112-1117. Link: https://goo.gl/mnLoLm

13. De Luca G, Suryapranata H, Stone G, Antoniucci D, Tcheng JE, et al. (2005) Abciximab as adjunctive therapy to reperfusion in acute ST-segment elevation myocardial infarction: a meta-analysis of randomized trials. JAMA 293: 1759-1765. Link: https://goo.gl/M4zwwd

14. Belle L, Motreff $P$, Mangin L, Rangé G2, Marcaggi $X$, et al. (2016) Comparison of immediate with delayed stenting using the Minimalist Immediate Mechanical Intervention approach in acute ST-segment-elevation myocardial infarction: The MIMI study. Circ Cardiovasc Interv 9: e003388. Link: https://goo.gl/yohkUh

15. Tang L, Zhou S, Hu X, Fang ZF, Shen XQ (2011) Effect of delayed vs immediate stent implantation on myocardial perfusion and cardiac function in patients with ST-segment elevation myocardial infarction undergoing primary percutaneous intervention with thrombus aspiration. Can J Cardiol 27: 541547. Link: https://goo.gl/BaeeVY

16. Cafri C, Svirsky R, Zelingher J, Slutky O, Kobal S, et al. (2004) Improved procedural results in coronary thrombosis are obtained with delayed percutaneous coronary interventions. J Invasive Cardiol 16: 69-71. Link: https://goo.gl/7r8i9g

17. Meneveau N, Seronde M, Descotes-Genon V, Dutheil J, Chopard R, et al (2009) Immediate versus delayed angioplasty in infarct-related arteries with TIMI III flow and ST segment recovery: a matched comparison in acute myocardial infarction patients. Clin Res Cardiol 98: 257-264. Link: https://goo.gl/SW1446

18. Kelbaek H, Hofsten DE, Kober L (2016) Deferred versus conventional sten implantation in patients with ST-segment elevation myocardial infarction (DANAMI 3-DEFER): An open-label, randomised controlled trial. Lancet 387 2199-2206. Link: https://goo.gl/GG5uak

19. Tang L, Zhou S, Hu X, Fang ZF, Shen XQ (2011) Effect of delayed vs immediate stent implantation on myocardial perfusion and cardiac function in patients with ST-segment elevation myocardial infarction undergoing primary percutaneous intervention with thrombus aspiration. Can J Cardiol 27: 541 547. Link: https://goo.gl/XAyt3p

Copyright: (c) 2019 Tabl MA, et al. This is an open-access article distributed under the terms of the Creative Commons Attribution License, which permits unrestricted use, distribution, and reproduction in any medium, provided the original author and source are credited. 